\title{
A Survey on Smart Grid-Connected Photovoltaic Power Systems and Its Issues
}

\author{
Sarika Gautami \\ MTech Scholar \\ Department of Electrical \& Electronics Engineering \\ Technocrats Institute of Technology, Bhopal \\ gautamisarika@gmail.com
}

\begin{abstract}
Photovoltaic power generation refers to the use of solar photovoltaic cells to the solar radiation can be directly transformed into electricity generation. Distributed photovoltaic power generation, refers to the construction in the vicinity of the user's location, the operation mode to the user side of spontaneous self-occupied mainly, the excess power on the Internet, and in the distribution system to balance the characteristics of the photovoltaic power generation facilities. Distributed photovoltaic power generation follow the principle of local conditions, clean and efficient, decentralized layout, the principle of the nearest use, and make full use of local solar energy resources, alternative and reduce fossil energy consumption. This paper aims to investigate and emphasize the importance of the grid-connected PV system. The investigation was conducted to critically review the literature on expected potential problems associated with issues of $\mathrm{PV}$ based grid system. The main purpose of this paper is to discuss the basic understanding of photovoltaic (PV) based distributed generation power system and how these power flows will influence the performance and stability of a power system. Some of the PV grid integration issues such as voltage regulation, voltage sags, harmonic distortion, etc are also discussed and possible solutions are also mentioned.
\end{abstract}

Keywords - Distributed Generation; Photovoltaic Power Systems; Smart Grid;

\section{INTRODUCTION}

Solar energy is vital for our planet. As a whole, it is the most perennial, silent, and nonpolluting source of energy. It has been responsible for all life forms on the planet for millions of years. It is the largest renewable energy source and the origin of many others on Earth such as: wind, hydro, photosynthesis, and superficial geothermic, sea thermal, and sea tides [1]. Solar energy can be directly or indirectly converted into electricity. Indirectly by transforming solar radiation into heat, vapor, and then electricity such as the large-scale applications using: parabolic plate, parabolic trough, or tower of energy to concentrate heat on a boiler with efficiency between 50 and $74 \%$. Directly by transforming solar light into electricity such as photovoltaic whose current commercial converting efficiency is between 3 and $25 \%$.

\author{
Rajeev Tiwari \\ Professor \\ Department of Computer Science and Engineering, \\ Bhopal, India \\ rajeevrnt@yahoo.in
}

The generation of photovoltaic electrical power with modules is constituted of many photovoltaic solar cells arranged in modules and arrays of modules. Every module must face South in the northern hemisphere and North in the southern hemisphere, depending on the local use interests. The recommended panel tilt angle can be calculated by using the site latitude plus $15-20^{\circ}$. Many algorithms of control have been proposed in the literature for interconnections of the individual cells to the connection of a full module or group of them to the grid. For best results, it is necessary to alter the interconnection schemes of each panel in a power system to find the best configuration to a given situation such as operations under intermittent shadows, network surges, load insertion, and other peculiarities. Power electronics, digital controls, and remote monitoring are the basis for production of electricity from solar radiation[2-5].

Photovoltaic cells convert solar radiation directly into DC electrical energy. The basic material for almost all the photovoltaic cells existing in the market, which is high purified silicon ( $\mathrm{Si}$ ), is obtained from sand or quartz. Basically, three types of technology are used in the production of photovoltaic cells: mono-crystalline; polycrystalline; and amorphous silicon. The crystalline-Si technology is commonly used as a reference, or baseline, for the solar power generation technology. In general, the status of a photovoltaic cell technology depends on the cell efficiency, and manufacturing cost [6]. The focus of $\mathrm{R} \& \mathrm{D}$ all over the world is on improving its efficiency and cost, where the optimal solution is based on a trade-off between the two. The efficiency of a photovoltaic cell is determined by the material's ability to absorb photon energy over a wide range, and on the band gap of the material. Photovoltaic cells are semiconductors that have weakly bonded electrons at a level of energy called valence band. When energy strikes this valence band, it frees those bonded electrons and moves them to another energy level called conduction band. At the conduction 
band, the electrons are able to conduct electricity through an electrical load. PV cells use the energy of photons from sunlight to break their band gap energy thereby producing DC current. Typically, PV cells produce low power (approximately 2-3Watts); hence several cells are connected together to form modules and panels for higher power applications. Power regulation elements (e.g. battery, charge controller, converter, etc.) mare also incorporated to match the output power form to the demanded application. Figure 1 shows the simple concept of photovoltaic system. The photovoltaic cell consists of several layers of semiconductor materials with different electronic properties .In a typical polycrystalline cell, the bulk of the material is silicon, doped with a small quantity of boron to give it a positive or p-type character.

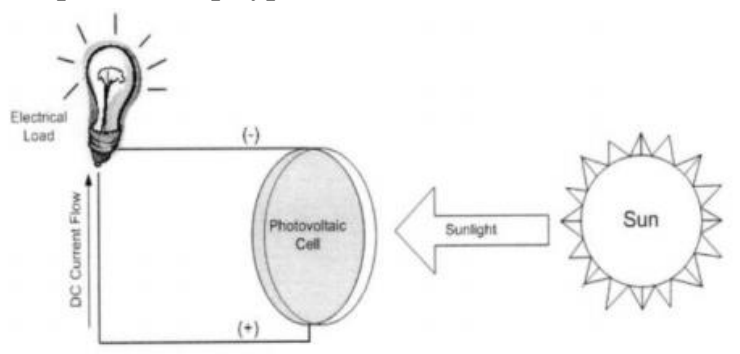

Figure 1: Photovoltaic System

A thin layer on the front of the cell is doped with phosphorous to give it a negative or n-type character. The interface between these two layers produces an electric field and forms the socalled a "cell junction"[7]. When the cell is exposed to sunlight, a certain percentage of the incoming photons are absorbed in the region of the junction, freeing electrons in the silicon crystal. If the photons have enough energy, the electrons will be able to overcome the electric field at the junction and are free to move through the silicon and into an external circuit. The Direction of the electric current is opposite to its direction if the device operates as a diode.

\section{ANALYSIS OF PHOTOVOLTAIC SYSTEM}

\section{A. Photovoltaic cell}

PV cell are basically semiconductor diode. This semiconductor diode has got a p-n junction which is exposed to light. When illuminated by sunlight it generates electric power [8]. PV cell are made up of various semiconductor materials. But monocrystalline silicon and poly-crystalline silicon are mainly used for commercial use.

\section{B. Photovoltaic module}

The power produced by a single PV cell is not enough for general use. So by connecting many single PV cell in series (for high voltage requirement) and in parallel (for high current requirement) can get us the desired power. Generally a series connection is chosen this set of arrangement is known as a module. Generally commercial modules consist of 36 or 72 cells [9]. The modules consist of transparent front side, encapsulated PV cell and back side. The front side material is usually made up of low-iron and tempered glass. The efficiency of a PV module is less than a PV cell. This is due to the fact that some radiation is reflected by the glass cover and frame shadowing etc.

\section{Photovoltaic Array}

A photovoltaic array (as shown in Figure 2) is an interconnection of modules which in turn is made up of many PV cells in series or parallel. The power produced by a single module is seldom enough for commercial use, so modules are connected to form array to supply the load. The connection of the modules in an array is same as that of cells in a module. Modules can also be connected in series to get an increased voltage or in parallel to get an increased current. In urban uses, generally the arrays are mounted on a rooftop. In agricultural use, the output of an array can directly feed a DC motor.

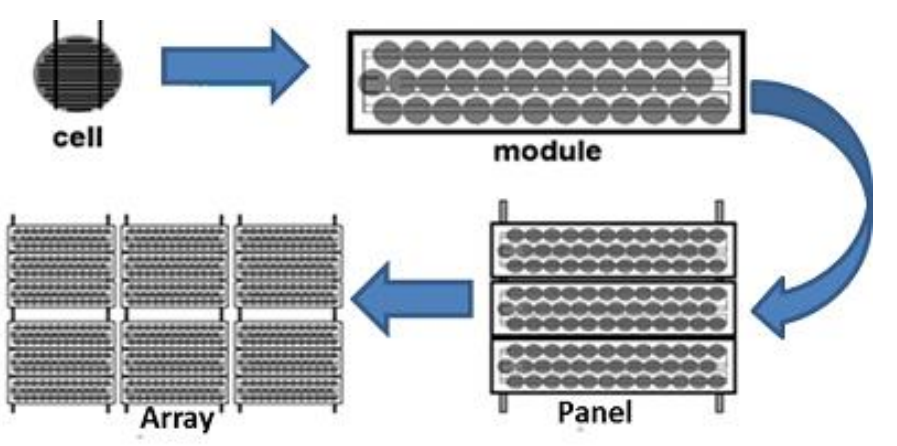

Figure 2: Photovoltaic Hierarchy

\section{Working of PV cell}

Working of a PV cell is based on the basic principle of photoelectric effect. Photoelectric effect can be defined as a phenomenon in which an electron gets ejected from the conduction band as a consequence of the absorption of sunlight of a certain wavelength by the matter (metallic or non-metallic solids, liquids or gases). So, in a photovoltaic cell, when sunlight strikes its surface, some portion of the solar energy is absorbed in the semiconductor material. If absorbed energy is greater than the band gap energy of the semiconductor, the electron from valence band jumps to the conduction band. By this, pairs of hole-electrons are created in the illuminated 
region of the semiconductor [10-12]. The electrons thus created in the conduction band are now free to move. These free electrons are forced to move in a particular direction by the action of electric field presents in the PV cells. These flowing electrons constitutes current and can be drawn for external use by connecting a metal plate on top and bottom of PV cell. This current and the voltage (created because of its built-in electric fields) produces required power.

\section{GRID CONNECTED PV SYSTEM}

Grid-connected PV systems include building integrated PV (BIPV) systems and terrestrial PV systems (including PV power plants in saline-alkali land, tideland and desert). At the scale of the entire interconnected electric power grid, generated electric power must be consumed within milliseconds of being generated [13]. Excess power can be accumulated with energy storage systems such as pumped hydro, but conventional energy storage systems respond much more slowly than the load changes so throttling back on peaking generation is used to stabilize the power flow into and out of the grid. In addition, when the load on the utility grid reaches new peak levels, the system operators must start activating every available generating source and even minor throttling back of generation may cause the grid voltage to collapse. The major elements of a grid-connected PV system that does not include storage are shown in Fig. 3. The inverter may simply fix the voltage at which the array operates, or (more commonly) use a maximum power point tracking function to identify the best operating voltage for the array. The inverter operates in phase with the grid (unity power factor), and is generally delivering as much power as it can to the electric power grid given the available sunlight and temperature conditions.

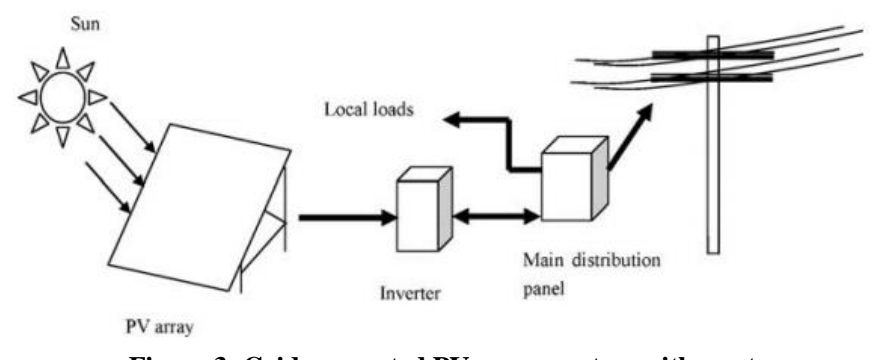

Figure 3: Grid-connected PV power system with no storage

The inverter acts as a current source; it produces a sinusoidal output current but does not act to regulate its terminal voltage in any way. The utility connection can be made by connection to a circuit breaker on a distribution panel or by a service tap between the distribution panel and the utility meter. Either way, the PV generation reduces the power taken from the utility power grid, and may provide a net flow of power into the utility power grid if the interconnection rules permit [14].

The typical structure of a grid connected PV unit is shown in Figure 4. Its main components are the PV array, the DC/DC, DC/AC converters and the associated (converter and overall system) controls. A storage device is absent in large gridconnected installations (except maybe for small critical loads).

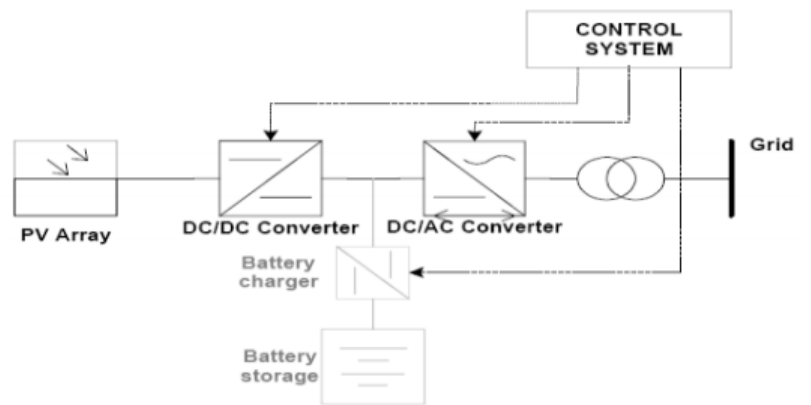

Figure 4: Typical Structure of a Grid Connected PV Generator

In Figure 5 the series resistance Rs represents the internal losses due to the current flow, whereas the shunt resistance Rsh corresponds to the leakage current to the ground and it is normally ignored. In an ideal cell $\mathrm{Rs}=\mathrm{Rsh}=0$, which is a common assumption. The equivalent circuit of a PV module, which consists of a combination of series and parallel connected cells, are the same.

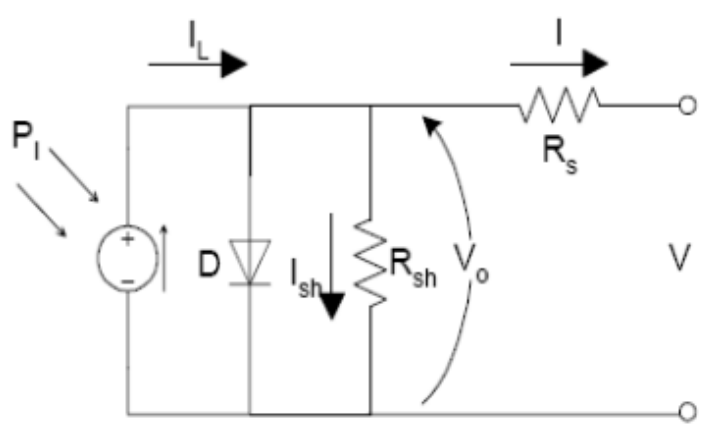

Figure 5: PV Cell Equivalent Circuit

The governing equations of the equivalent circuit are:

$\mathrm{V}=\mathrm{V}_{0}$-RSI

$\mathrm{I}=\mathrm{I}_{\mathrm{L}}-\mathrm{I}_{\mathrm{D}}\left(\mathrm{e}^{(\mathrm{qV} 0 / \mathrm{AKT})}-1\right)-\mathrm{I}_{\mathrm{sh}}$

$\mathrm{I}_{\mathrm{sh}}=\mathrm{V}_{0} / \mathrm{R}_{\mathrm{sh}}$

$\mathrm{Il}=\mathrm{I}_{\mathrm{sc} 1}\left(\mathrm{P}_{1 / 1000}\right)$

Where: V, I - output voltage and current

$\mathrm{q}$ - Electron charge $(1.6 * 10-19 \mathrm{Cb})$

$\mathrm{k}$ - Boltzmann constant $(1.38 * 10-23 \mathrm{~J} / \mathrm{K})$

$\mathrm{T}$ - Temperature in $\mathrm{K}$ 


\section{ISSN: 2349-0772 | Volume IV Issue III June 2017|www.ijosthe.com}

A - Quality factor (constant)

$\mathrm{I}_{\mathrm{D}}-$ reverse saturation current of the diode

$\mathrm{I}_{\mathrm{L}}$ - photocurrent, dependent on $\mathrm{T}$

$\mathrm{P}_{\mathrm{I}}$ - insolation level in $\mathrm{W} / \mathrm{m} 2$

$\mathrm{I}_{\mathrm{sc} 1}-$ short circuit current at $1000 \mathrm{~W} / \mathrm{m} 2$ solar radiation

Multiple PV modules are connected in series and in parallel to form the PV array. Similar equations hold for the whole array, provided that all modules are identical and subject to the same isolation [15].

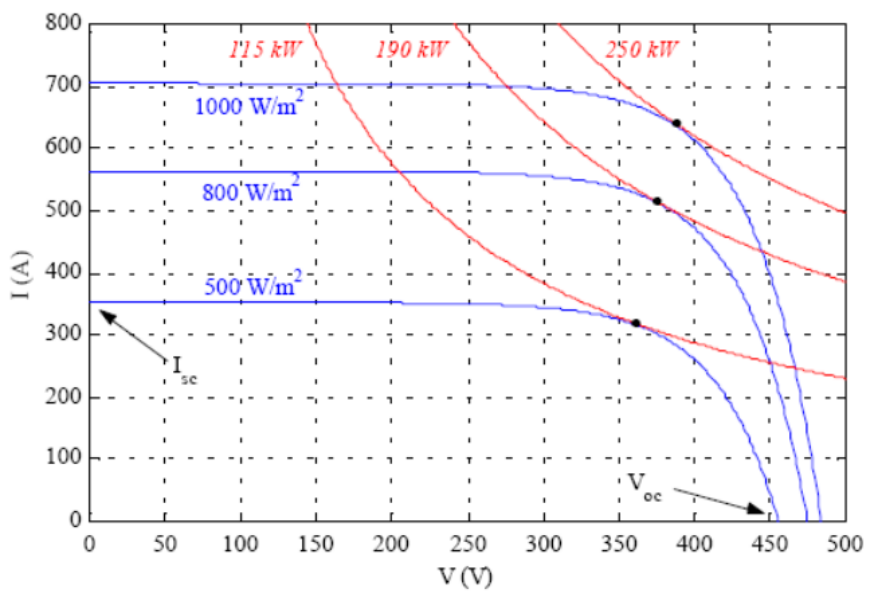

Figure 5: Typical PV array V-I characteristics

The V-I characteristics of a $250 \mathrm{Kw}$ array are shown in Figure 6 at three solar radiation (PI) levels. On the same diagram three constant power curves (red lines) have been drawn. It is clear that, for a given isolation, the array produces maximum power only when operating near the knee point of the corresponding V-I curve (maximum power point). The task of tracking the maximum power point (MPPT) is usually performed by a DC/DC converter at the output of the array, which regulates the voltage to the desired value. Since no moving parts are employed in this process, the response of the MPPT can be considered instantaneous for system studies [16].

A device that may affect the response of the PV generator output in case of solar radiation changes is the sun-tracking system of the panels, which adjusts the orientation of the panels with respect to the sun, a task performed by the use of properly controlled servomotors. However, these are relatively slow acting devices and may be ignored in transient stability studies. As discussed, the remaining system components (dc bus, inverter and grid-connection devices) are of similar nature and characteristics as for other dispersed generators (e.g. variable speed wind turbines) as are the modeling requirements [17].

\section{PV SYSTEMS GRID INTEGRATION ISSUES}

Renewable energy sources are intermittent in nature hence it is therefore a challenging task to integrate renewable energy resources into the power grid. Some of the challenges and issues associated with the grid integration of various renewable energy sources particularly solar photovoltaic conversion systems. Further these challenges are described below:

- Cost

- Reliability \& Efficiency of Grid Interface

- Grid congestion, weak grids

- Variability of renewable production

- Low Power Quality

- Change of short circuit levels

- Reverse power flow

- Lack of sustained fault current

- Islanding

- Bidirectional power flow in distribution network

- Localized voltage stability problems

The integration of solar energy into existing power system presents technical challenges such as voltage regulation, flicker, harmonic distortion, stability etc, these power quality issues are to be confined to IEC and IEEE standards. A review of many papers of last few years shows that these power quality issues can occur at the generation, transmission and distribution [14]. The different power quality problems have been discussed in different papers and some of them is given below.

\section{A. Voltage Regulation}

The droop characteristics are used, particularly for DFIGs to control the voltage magnitude and frequency [6]. This can be extended to WECS by doing a voltage sensitivity analysis to achieve voltage regulation at PCC. The high DC bus ripple is a result of the voltage-drive mode to provide the best $\mathrm{AC}$ power quality [6] and concludes that the bidirectional power flow and the bottom-up decentralized control methods make DG systems are well controlled and organized. To overcome this problem in [7] author focuses on the grid-interfacing architecture, with fuzzy logic controllers to improve voltage quality. For wind generators is landed micro grid. Here, the complex power droop the unbalances control systems use a virtual impedance loop to compensate. 


\section{B. Voltage Sags/ Swells}

The operation of Sensitive loads connected to the grid is influenced by the voltage dips. To overcome this disadvantage author presented power electronic converter in [8] using a series compensator, which requires considerably less active power and is able to restore the voltage at the load side. Gridinterfacing power quality compensator for three-phase fourwire micro-grid applications was developed using the sequence components to inject voltages as a complementary measure Under the Net-metering scenario a Power Quality Control Center (PQCC) would regulate voltage due to the reversal of power flows from the DG and the increase in short circuit current [9].

\section{Harmonics}

The grid interaction and grid impact of wind turbines have been focused on during the past few years. The reason behind this interest is that wind turbines are among the utilities considered to be potential sources of bad power quality. Especially, variable-speed wind turbines have some advantages concerning flicker. But, a new problem arose with variable-speed wind turbines. Modern forced-commutated inverters used in variable-speed wind turbines produce not only harmonics but also inter harmonics. The International Electro technical Commission (IEC) initiated the standardization on the power quality for wind turbines in 1995 as part of the wind-turbine standardization in TC88, and ultimately 1998 IEC issued a draft IEC-61400-21 standard for "power quality requirements for Grid Connected Wind Turbines" [10]. Recently, high-frequency (HF) harmonics and inter harmonics are treated in the IEC 61000-4-7 and IEC 61000-3-6 [11], [12]. The methods for summing harmonics and inter harmonics in the IEC 61000-3-6 are applicable to wind turbines. In order to obtain a correct magnitude of the frequency components, the use of a well defined window width, according to the IEC 61000-4-7, Amendment 1, is of a great importance, as has been reported in [13]. In [14] author introduces a new Adaptive Notch Filtering (ANF) approach which can address issues like, extracting harmonics, voltage regulation, complex power control, suppressing frequency variations and noise contents using the sequential components of voltages as reference. Some methods for harmonic damping are presented in [15] such as (i) a shunt harmonic impedance method adaptable for islanded micro-grids application, (ii) The voltage-based droop control strategy to have controllable harmonic current and PQ (iii) heuristic Optimization techniques such as differential evolution algorithm (DEA) are used to obtain the switching states of CPDs, as a nonlinear optimization problem.

\section{Real and Reactive Power}

The seasonal patterns and the diurnal variations of wind are to be addressed for grid connected wind turbine (GCWT) systems to achieve high-quality power from inverters meeting the specifications of grid codes. A droop control method is proposed based on the reactive power produced by the negative-sequence current and the positive-sequence line voltage [16]. A variant of the droop control strategy is used in [17], which combines $\mathrm{P} / \mathrm{V}$ droop control with voltage droops to control the active power. A Lyapunov-function-based current tracking controller is proposed to control both active and reactive power flow for parallel-connected inverter. The THD levels were found satisfactory even for nonlinear loads.

\section{E. Power System Stability Problem}

The power system stability can be classified into: rotor (or power) angle stability; (ii) frequency stability; and (iii) voltage stability. Hence, different viewpoints are introduced concerning the stability issues raising different types of stability problems including "Rotor angle stability", "Frequency stability" and "Voltage stability". Rotor angle stability is concerned with the system ability to maintain the equilibrium between electromagnetic torque and mechanical torque of each generator in the system. Instability that may result occurs in the form of increasing angular swings of some generators leading to their loss of synchronism with other generators Voltage stability is concerned with the ability of a power system to maintain its steady voltage at all buses in the system under normal operating conditions, and after subjecting to a disturbance. [18]- [20].

\section{POSSIBLE SOLUTIONS}

The renewable energy sources such as solar has accelerated the transition towards greener energy sources. The increasing number of renewable energy sources and distributed generators requires new strategies for the operation and management of the electricity grid in order to maintain or even to improve the power-supply reliability and quality. Keeping in view of the aforesaid some of the possible solutions have been proposed by researchers. The power-electronic technology plays an important role in distributed generation 
and in integration of renewable energy sources into the electrical grid, and it is widely used and rapidly expanding as these applications become more integrated with the gridbased systems. During the last few years, power electronics has undergone a fast evolution, which is mainly due to two factors. The first one is the development of fast semiconductor switches that are capable of switching quickly and handling high powers. The second factor is the introduction of realtime computer controllers that can implement advanced and complex control algorithms. These factors together have led to the development of cost- effective and grid-friendly converters.

\section{CONCLUSION}

In this paper, introduction of PV based grid integration have been presented. Various protection issues that arise when photovoltaic system is integrated in to the main grid are discussed and analyzed in this Paper. The causes, affects, mitigation technologies featuring their topologies, highlighting the advantages of the grid integrated solar and particularly wind power systems are examined. To minimize the fluctuations and intermittent problems power electronics devices are the viable options. To solve such issues of low and fluctuated power operation of distributed generation units, if the grid connected interface equipment can be put into market quickly, it will produce considerable economic benefits.

\section{REFERENCES}

[1] Ishikawa T. Grid-connected photovoltaic power systems: survey of inverter and related protection equipments. Report IEA (International Energy Agency) PVPS T5-05; 2002. http://www.iea-pvps.org.

[2] Zhao Y, Wang S, Li X, Wang W, Liu Z, Song S. China renewable energy development project. Report on the development of the photovoltaic industry in China. NDRC/GEF/WB, August; 2006.

[3] Trends in Photovoltaic Applications. Survey report of selected IEA countries between 1992 and 2003, Photovoltaic. Power Systems Program. Report IEAPVPS T1-13: 2004; 2004.

[4] Calais M, Myrzik J, Spooner T, Agelidis VG. Inverters for single-phase grid connected photovoltaic systems - an overview. In: IEEE power electronics specialists conference PESC'01; 2001.

[5] Andrew J. Roscoe, Stephen J. Finney, and Graeme M. Burt, "Tradeoffs Between AC Power Quality and DC Bus Ripple for 3- Phase 3-Wire Inverter-Connected Devices Within Microgrids", IEEE Transactions on power electronics, Vol. 26, No. 3, March 2011.

[6] Fei Wang, Jorge L. Duarte, and Marcel A. M. Hendrix, "GridInterfacing Converter Systems With Enhanced Voltage Quality for Microgrid Application-Concept and Implementation", IEEE Transactions on power electronics, Vol. 26, No. 12, December 2011.

[7] Koen J. P. Macken,Math H. J. Bollen and Ronnie J. M. Belmans, "Mitigation of Voltage Dips Through Distributed Generation Systems" IEEE Transactions on industrial aplications, Vol. 40, NO. 6, Nonember/December 2004.

[8] Y. Q. Zhan, S. S. Choi, and D. Mahinda Vilathgamuwa "A Voltage-Sag Compensation Scheme Based on the Concept of Power Quality Control
Center", IEEE Transactions On Power Delivery, Vol. 21, No. 1, January 2006.

[9] D. Foussekis, F. Kokkalidis, S. Tentzevakis, and D. Agoris, "Power quality measurement on different type of wind turbines operating in the same wind farm," presented at the EWEC (Session BT2.1 Grid Integration), Madrid, Spain, Jun. 16-19, 2003.

[10] Electromagnetic Compatibility, General Guide on Harmonics and Interharmonics Measurements and Instrumentation, IEC Standard 61000-4-7, 1997.

[11] Electromagnetic Compatibility, Assessment of Emission Limits for Distorting Loads in MV and HV Power Systems, IEC Standard 61000-3.

[12] L. Ake, S. Poul, and S. Fritz, "Grid impact of variable speed wind turbines," in Proc. EWEC, 1999, pp. 786-789.

[13] Davood Yazdani, Alireza Bakhshai, Geza Joos, and M. Mojiri, "A Nonlinear Adaptive Synchronization Technique for GridConnected Distributed Energy Sources" IEEE Transactions on power electronics Vol. 23, NO. 4, July 2008.

[14] Ine Vandoorn, Bart Meersman, Jeroen De Kooning, and Lieven Vandevelde, "Controllable Harmonic Current Sharing in Islanded Microgrids: DG Units With Programmable Resistive Behavior Toward Harmonics" IEEE Transactions on Power Delivery, Vol. 27, No. 2, April 2012.

[15] Po-Tai Cheng, Chien-An Chen, Tzung-Lin Lee, and Shen-Yuan Kuo "A Cooperative Imbalance Compensation Method for DistributedGeneration Interface Converters" IEEE Transactionson Industry Applications, Vol. 45, No. 2, March/April 2009.

[16] Tine L. Vandoorn Bert Renders,Lieven Degroote, Bart Meersman,, and Lieven Vandevelde, "Active Load Control in Islanded Microgrids Basedonthe Grid Voltage" IEEE Transactions on Smartgrid Vol. 2, No. 1, March 2011.

[17] P.Vijayan and S.Sarkar, and V. Ajjarapu, "A Novel Voltage Stability Assessment Tool to Incorporate Wind Variability", Power \& Energy Society General Meeting, 2009.PES '09. IEEE 26-30 July 2009.

[18] Mohsen Rahimi, Mostafa Parniani, "Dynamic behavior and transient stability analysis of fixed speed wind turbines", Renewable Energy 34 (2009) 2613-2624.

[19] F. Wua, X.-P. Zhangb, P. Jua, "Small signal stability analysis and control of the wind turbine with the direct-drive permanent magnet generator integrated to the grid", Electric Power Systems Research 79 (2009) 1661-1667.

[20] Wang Shandan, Bo Zhao, Xu Xiaoyu, "Indroduction to Distributed Photovoltaic Power Generation Flexible Grid-Connection Interface Equipment Research", IEEE, 2016: 285-288. 